\title{
The Mágina Project. The renewables potential for electricity production in the province of Jaén, southern Spain
}

\author{
J. Terrados ${ }^{1, *}$, J.A. Ruiz-Arias ${ }^{2}$, L. Hontoria ${ }^{3}$, G. Almonacid ${ }^{2,3}$, P.J. Pérez, D. Pozo- \\ Vázquez $^{4}$, F.J. Gallego ${ }^{1}$, P. Gómez ${ }^{5}$, E. Castro ${ }^{6}$, A. Martín-Mesa ${ }^{7}$, M.J. del Jesús ${ }^{8}$ \\ ${ }^{1}$ Dept. Graphic Engineering, Design and Projects, University of Jaén, Jaén, Spain \\ ${ }^{2}$ Commissioner for the Centre of Advanced Studies in Energy and Environment \\ ${ }^{3}$ Dept. Electronic and Automatic Engineering \\ ${ }^{4}$ Dept. Physics \\ ${ }^{5}$ Dept Electric Engineering \\ ${ }^{6}$ Dept. Chemical, Environment and Material Engineering \\ ${ }^{7}$ Dept. Economy \\ ${ }^{8}$ Dept. Computer Science \\ * Corresponding author. Tel: +34 953212825, Fax: +34 953212334, E-mail: jcepeda@ujaen.es
}

\begin{abstract}
Nowadays, the global energy generation system relies mostly on fossil fuels. However, their foreseen depletion for the forthcoming decades puts at risk the current schema and suggests a gradual transition to a more self sustainable system. Consequently, the European Union (EU) committed in March 2007 to set a binding target for $20 \%$ of the EU's total energy supply to come from renewables by 2020. In this work, we tackle the study of the renewables' potential for electricity production in the province of Jaén (southern Spain), which has a pronounced unbalance between its inner electricity production and consumption. The potential of biomass from olive trees, solar photovoltaic (PV) and wind power has been analyzed using Geographical Information System tools. As a preliminary result, it has been proposed the installation of 5 biomass facilities, with an estimated production of $735 \mathrm{GWh}$ per year, $10 \mathrm{PV}$ facilities, with an estimated production of $534 \mathrm{GWh}$ per year, and 50 windmills, with an estimated production of $172 \mathrm{GWh}$ per year. Overall, these three resources together would be able to increase the rate of produced to consumed electricity in the province from a $30 \%$ to a $77 \%$.
\end{abstract}

Keywords: renewable energies, electricity, distribution grid, regional development

\section{Introduction}

The foreseen depletion of fossil resources is forcing us to seek for new energy springs. However, the climate change issue claims for non-pollutant solutions that help in mitigating the global warming. Even more, due to the world's economic development, it is expected that the worldwide demand for electricity will increase by $80 \%$ between 2006 and 2030 [1]. This global scenario makes unavoidable the transition to more and more renewable energy shares.

Therefore, promotion of renewable energies will play a major role as it is also indicated by the European Union (EU) objectives by 2020. They set a binding target for 20\% of the EU's total energy supply to come from renewables by 2020 (6.5\% in 2007). Furthermore, they set a firm target of cutting 20\% of the EU's greenhouse gases emissions by 2020 relative to 1990 . Additionally, Europe has a marked dependence on outer energy imports (50\%) provided its lack of own fossil resources. In Spain, particularly, the dependence is even higher, reaching the $85 \%$. Hence, the national government has promoted in the last years the renewables through various ambitious national plans [2] which, additionally, pretend to accomplish with the EU's commitments through, among other, a 30\% target contribution of renewables for electricity production.

The province of Jaén is situated in the southern part of the Iberian Peninsula (Fig. 1). It occupies an extension of roughly $13500 \mathrm{~km}^{2}$ with a population totaling 669000 inhabitants. Its economy is principally based on the olive oil industry. Actually, the olive oil production in Jaén is the $20 \%$ of the worldwide production and the $50 \%$ of the Spanish one. Its territory is 
divided in two different topographic regions: the south-eastern and the northern façades, which are traversed by mountainous systems, and the region in between, a well-flat area which houses the higher part of the Guadalquivir river basin. The highest peak is the Mágina Peak, in the southern façade, with 2167 meters above sea level.
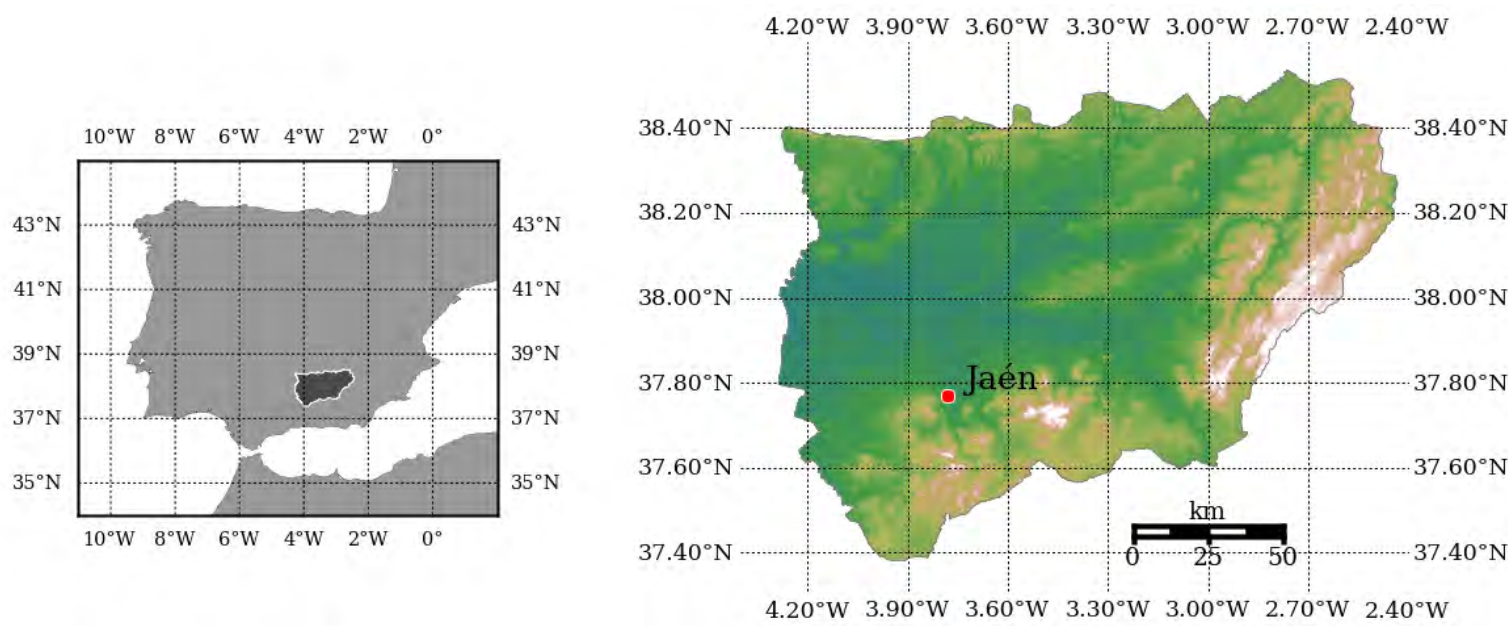

Figure 1. Geographical location and topography of the province of Jaén.

As the rest of Europe and Spain, Jaén has a high dependence on fossil fuels. As far as electric energy concerns, the region has a negative balance in production/consumption. Particularly, in 2008 the actual inner production of electricity was only about 940 GWh, against a consumption of about $3080 \mathrm{GWh}$ in this same period [3]. This situation strongly contrasts with the rest of Spain, where the electricity production/consumption is well-balanced. Particularly, in 2008, total production and consumption were about 296000 and 275000 GWh, respectively [3].

In order to correct this unbalance in the province, fossil fuels should not be a choice. Instead, local renewable resources are a real alternative with huge potential still to be developed. However, in spite of the high potential, currently, about $84 \%$ of the electricity is produced in thermal plants, most of them, combined heat and power plants. Out of this $84 \%$, only a small rate comes from biomass residuals. The rest of the electricity share is produced by hydropower stations (9\%), solar photovoltaic (PV) (4\%) and wind power (3\%) [3].

Biomass is an important energy spring in the province, mainly, from agricultural residuals as prune wastes and olive stones, for instance. Currently, it represents around a $20 \%$ of the primary energy consumption, mainly for heating [4]. However, just the biomass from the olive prune is estimated to be about 3 tons per hectare and year [5]. Hence, the more than 600000 ha of olive crops in the province are a resource that deserves to be exploited. Additionally, the province also has a considerable potential from solar and wind resources. Particularly, Jaén is one of the sunniest regions in Spain, with more than 1700 sunshine hours a year. The electric production from wind farms is also a feasible approach as it has been already demonstrated by some plants that operate in the region.

In this work, we intend to tackle an estimation of the real potential for electricity production in the province of Jaén from local renewable resources: biomass, solar PV and wind power. It pretends to be a solid background to develop an optimum plan for a massive intervention in the electric grid that correct the current unbalance between electricity production and consumption based purely on renewable energies. We here propose a preliminary distribution 
of the production plants based on multiple criteria as the resources distribution, availability of feed-in points in the grid or even distribution of the plants along the region. However, this initial distribution is still subject to modifications based on on-going tasks, as a deeper investigation of the current state of the local electric grid or environment and economic issues.

\section{Methodology}

Firstly, the different resources availability has been independently evaluated using a suitable approach in each case. Afterwards, they have been jointly analyzed by using geographical information systems (GIS) tools. With these tools, digital models with the spatial distribution of the resources have been created considering restrictive criteria as topographic features or soil type and use. These maps allow estimating the real potential for electricity production from renewable resources and a subsequent analysis based on environment, social and economic criteria; currently, an on-going task.

\subsection{Biomass potential from olive tree residuals}

This part of the study has involved two different stages: (i) the evaluation of the total amount of biomass residuals available from olive trees and, (ii) the evaluation of the electric performance that could be achieved.

The first stage required an intensive use of GIS tools. Firstly, soil use maps of the province were used to isolate the olive crops in the region. Among them, only those areas with a terrain slope less than $20 \%$ were considered as useful for exploitation. The rationale behind is that terrains with higher slopes make difficult the use of agricultural machinery, thus considerably increasing the management and transport costs of the residuals. Once the total (useful) area of olive crops available for exploitation was determined $\left(S_{\text {crops }}\right)$, the total amount of residuals ( $B R$, biomass residuals in $\mathrm{kg}$ per year) was evaluated based on the biomass residuals production index $(B R I)$ for olive trees. It indicates the biomass residuals availability per ha and per year. Therefore:

$B R=S_{\text {crops }} \times B R I$

The value of the BRI parameter for olive trees was extracted from previous research works conducted by the Andalusian Energy Agency and the Agricultural Department of the Regional Government of Andalusia [6, 7]. Following the recommendations of these studies, two different $B R I$ values were used for irrigated and dry lands. This terrain classification was conducted based also on the soil use maps of the region.

In order to assess the potential electricity that can be generated from these biomass residuals, we were based in the operation data accumulated in some biomass plants that are already operating in the province and the rest of Spain.

\subsection{Photovoltaic potential}

The solar PV potential assessment also implied a two steps procedure: (i) the evaluation of the solar resource potential and, (ii) the electricity potential generation based on the resource availability.

In order to evaluate the solar resource, the clear-sky solar radiation model of the European Solar Radiation Atlas (ESRA) was used in its version implemented in the GRASS GIS 
platform [8]. The ESRA model has been profusely used in practical applications as the determination of solar radiation maps from satellite imagery [9] or the generation of databases from ground measurements as the PVGIS web platform. This model parameterizes the effect of the atmosphere based on the Linke turbidity coefficient $\left(T_{L}\right)$, which represents the number of Rayleigh atmospheres radiatively equivalent to the actual atmosphere. The Linke turbidity is a climatic and dimensionless parameter which has been traditionally calculated on a monthly basis from satellite and ground measurements. It is freely available in wide databases as the SODA dataset.

The second step involved the assessment of the potential electricity produced from this solar resource. The evaluation was based on a traditional fixed PV system with panels inclined $30^{\circ}$ degrees over the horizontal and permanently oriented to the south. This reference configuration is close to the optimal for the latitudes of the region, thus enabling us to estimate the real PV potential. The recovered energy, $E_{P V}$, was estimated considering the practical rule that installation of $1 \mathrm{MW}_{\mathrm{p}}$ requires approximately a parcel of 2 ha. Therefore:

$E_{P V}=\frac{G}{G_{p}} \frac{1 M W_{p}}{2 h a} P_{R}$

where $G$ is the total irradiance that strikes the PV panel, $G_{p}=1000 \mathrm{Wm}^{-2}$ and $P_{R}$ is the performance ratio, which accounts for the different system losses. Based on our own experience, we took $P_{R}=75 \%$.

The use of this methodology presents various advantages. On the one hand, as the model is integrated within a GIS, it is able to account for the topographic shading effect of surrounding terrain elevations. On the other hand, it allows us to calculate the solar radiation components with a high temporal resolution (in this case, every 12 minutes) which is essential to evaluate the total solar radiation on the tilted plane of the PV panels. Nevertheless, note that the clearsky model is not accounting for the extinction caused by clouds. Thus, an evaluation of the model has been carried out based on long-term measurements of global solar radiation in the study region.

\subsection{Wind potential}

As in the former cases, the assessment has involved two steps: (i) the evaluation of the wind potential in the region and, (ii) the evaluation of the potential electricity that can be obtained from this resource.

Wind is a highly fluctuating resource both in space and time. This makes very difficult its estimation over a wide region exclusively from ground measurements since it would be required too many experimental stations which, additionally, should also record the wind at different altitudes above surface (typically, from 20 to 80 meters). Overall, this approach is often prohibitive from the economic point of view. Therefore, nowadays, the use of numerical weather prediction models is a common practice. They are able to generate comprehensive long-term data bases of the state of the atmosphere at high spatio-temporal resolutions. To do it, they make a spatial and temporal disaggregation based on physical laws (known as dynamical downscaling) over the previously assimilated datasets from worldwide measurements of the atmosphere. 
In this study, we have used the Weather Research and Forecast (WRF) model [10], one of the most profusely used models for regional weather studies. A simulation over the southern half of the Iberian Peninsula was conducted for the whole 2007, thus avoiding boundary effects over the province of Jaén. The output was saved every $9 \mathrm{~km}$ and every hour. In the vertical, which is very important for wind assessment, the atmosphere was described based on 27 unevenly-distributed layers. A higher layers-density was set near the surface in order to achieve a better description of the turbulent transport processes that occur in these regions, which give rise to a high variability of the wind profile near the ground. Since most of the current windmills install their turbines at, roughly, 80 meters above surface, the output for wind speed from WRF was interpolated every hour at this vertical level. Afterwards, a refinement of the maps was carried out by spatial interpolation up to a grid spacing of 3 arc minutes (approximately, $5.4 \mathrm{~km}$ ).

Finally, the wind potential for electricity generation was based on the power curves of two standard commercially available windmills developed by Gamesa (http://www.gamesa.es). If the power curve, $P(v)$, of the wind turbine is known, the potential energy generated, $E_{W}$, can be easily calculated from the local wind speed distribution, $\Phi(v)$, as:

$E_{W}=\int_{v_{s}}^{v_{c}} \Phi(v) \mathrm{P}(v) d v$

where $v_{s}$ is the velocity at which the turbine starts to work and $v_{c}$ is the cut-off velocity, above which it is locked for safety. Usually, the performance and suitability of a windmill in a given placement is measured based on the number of equivalent hours, $H_{e}$, which represents the number of hours that the wind turbine must be working at maximum power, $P_{n}$, in order to produce the actual energy which is produced along a natural year. It is calculated as $E_{W} / P_{n}$.

\section{Results}

Results will be presented separately for each resource: biomass, solar PV and wind power.

\subsection{Biomass energy}

The total area of olive crops in the province amounts to 680000 ha and, up to 482000 ha of them correspond to useful terrains for exploitation (terrain slope below 20\%). The BRI values, given as a function of the terrain slope and for irrigated and non-irrigated lands, are shown in Table 1.

Table 1. Biomass residuals production index for olive crops in tons per ha per year.

\begin{tabular}{ccc}
\hline Terrain Slope & Dry crops & Irrigated crops \\
\hline less than $10 \%$ & 1.6 & 1.7 \\
greater than $10 \%$ & 1.4 & 1.6 \\
greater than $20 \%$ & & excluded \\
\hline
\end{tabular}

According to these values, the total potential volume of biomass residuals from olive crops was found to be about 720000 tons per year. After revising the historical production records of some biomass power plants which are already operating in Spain, it was concluded that facilities with a power of 16 and 25 MW consume around 120000 and 170000 tons per year, respectively. Therefore, multiple number and size of facilities, as well as different distribution layouts, could be selected. In this case, using GIS techniques, three different schemes were evaluated considering multiple criteria as: volume of biomass residuals available in the 
proximities of the plant, ease access to the facilities with heavy machinery, ease access to feed-in points in the grid or distance to cities. Particularly, the different layouts tested were: (i) 4 plants of $25 \mathrm{MW}$, (ii) 6 plants of $16 \mathrm{MW}$ and (iii) 2 plants of $16 \mathrm{MW}$ and 3 plants of 25 MW. The latter probed to be the best one according to the criteria established. Table 2 shows the operating details for each plant and Fig. 2 shows their geographical distribution and influence area.

Table 2. Installed power, biomass consumption and electricity production of the biomass power plants proposed in this study.

\begin{tabular}{cccc}
\hline $\begin{array}{c}\text { Facility } \\
\text { (nearest city) }\end{array}$ & $\begin{array}{c}\text { Installed Power } \\
\text { (MW) }\end{array}$ & $\begin{array}{c}\text { Biomass consumption } \\
\text { (tons/year) }\end{array}$ & $\begin{array}{c}\text { Production } \\
\text { (GWh/year) }\end{array}$ \\
\hline Linares & 25 & 167411 & 187.5 \\
Vva. del Arzobispo & 16 & 115349 & 120.0 \\
Peal del Becerro & 16 & 115349 & 120.0 \\
Arjonilla & 16 & 115349 & 120.0 \\
Martos & 25 & 167411 & 187.5 \\
\hline Total & 98 & 680867 & 735.0 \\
\hline
\end{tabular}

\subsection{Solar PV energy}

The solar radiation potential was estimated using the ESRA's clear-sky model, which does not account for the very important role of the clouds. In order to evaluate the validity of this approach, the clear-sky estimates were compared against a 5 years-length record of global solar radiation data registered at the experimental station of the University of Jaén. During spring and summer months, when the solar resource is higher, the difference between the measurements and the model keeps always below $1 \mathrm{kWhm}^{-2}$. During the 5 years record, the experimental station registered an average daily value of $5.95 \mathrm{kWhm}^{-2}$, while the corresponding simulated value was $5.50 \mathrm{kWhm}^{-2}$. Interestingly, the simulated value is below the observed one. This seems to indicate that SODA database reported an excessively high value in the province over the whole year. Anyway, the annual error is below $8 \%$.
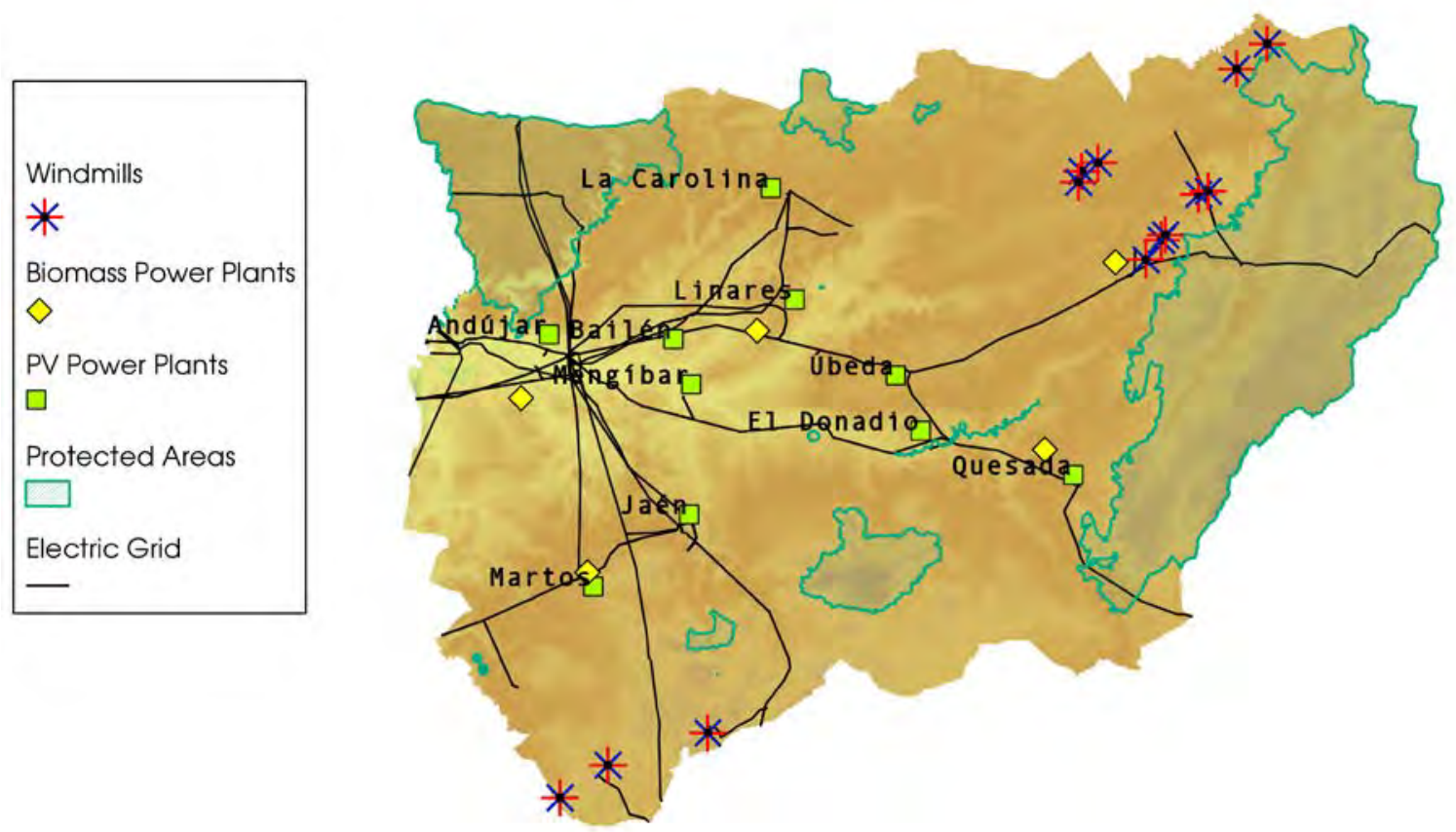

Figure 2. Proposed distribution of the biomass, PV and wind power plants. 
The difference between the maximum and the minimum yearly sum of irradiance over the whole region is a $5 \%$. This is attributable to the topographic spatial variability caused by the mountains. In the flat area over the Guadalquivir river basin, the solar resource is relatively homogeneous around $2075 \mathrm{kWhm}^{-2}$, which is equivalent to a PV generation of $78 \mathrm{kWhm}^{-2}$. Extended over the whole province, the PV potential is more than 300 times higher than the annual consumption of electricity in the region.

Based on these results, we propose the installation of 350 MWp spread over 10 PV facilities. Overall, these power plants would produce 534 GWh per year, occupying around $70 \mathrm{~km}^{2}$, the $0.5 \%$ of the province's extension. Again, GIS tools have been used to delimitate those areas useful for housing the power plants. Now, based on soil use and type, the next areas were excluded: urban, industrial, leisure and commercial areas, dumping sites and wet, irrigated and protected lands. Finally, the PV plants were distributed as shown in Fig. 2 based on the next criteria: (i) the plants must be close to suitable feed-in points, (ii) they must be evenly distributed over the electric grid and, (iii) complementary to the windmills sites proposed in the next section.

\subsection{Wind energy}

In average, according to the simulation with the WRF model, the areas with the highest wind speed at 80 meters above surface are the southern and eastern mountainous systems. This result shows the existence of a certain complementarity with the PV solar energy, which is more suitable in flat lands without topographic shading. The yearly average wind speed over the mountains ranges from 6.5 to $7.5 \mathrm{~ms}^{-1}$. In the flat areas around the river basin, the resource drops up to $4 \mathrm{~ms}^{-1}$.

The amount of electricity that can be generated from this resource depends on the wind turbine which be used. We selected two commercially available standard windmills, the G80 and the G87, developed by Gamesa, with the turbine placed at 80 meters above surface. Both windmills give a maximum (nominal) power of 2 MW. By using Eq. (3) we calculated the energy produced by each turbine over the whole province and, then, the number of equivalent hours. Overall, the G87 model fitted better the local wind resources. Particularly, all mountains in the province have more than 1500 equivalent hours and, the eastern façade, more than 2000 hours.

Deployment of wind farms must accomplish a severe environmental normative. Actually, it is usual that several projects be rejected by the competent authority. Therefore, in this study, we based our proposal for the wind farms distribution on a previous work carried out by the provincial department of energy of Jaén [11] which describes a series of sites that already account with legal support for its suitability to house small wind farms. Overall, the installation of 50 windmills over 13 small wind farms is proposed (Fig. 2). All of them are placed along the south - south-eastern façades of the province, outside protected natural parks. The average number of equivalent hours is 1702 and the estimated amount of electricity generated with these wind turbines is about $172 \mathrm{GWh}$.

\section{Discussion and conclusions}

Compared to Andalusia and the rest of Spain, the province of Jaén has a marked unbalance between its inner electricity production and consumption. Nevertheless, it has a promising potential to increase its production quota based solely on local renewable resources which, additionally, contribute to reduce pollutant emissions to the environment. On the one side, its 
industry is mainly based on the olive oil, being the major worldwide producer. This industry generates a huge amount of wastes that can be used as fuel in biomass power plants. On the other side, the province also counts with large solar and wind resources.

In this work, we have analyzed the potential for producing electricity from these three renewable sources. We have study a preliminary distribution of the production plants based on geographical and territory criteria. Hence, it is worth to note that this proposal does not aim to be the optimal energy mix in the region since we are not considering social and economic constraints, for instance. Overall, with this proposal, around 1450 GWh could be produced every year. Consequently, the rate of produced to consumed electricity would increase from a $30 \%$ to a $77 \%$. At the same time, the use of renewables instead of fossil-fuelbased technologies, would avoid the emission of almost one million tons of $\mathrm{CO}_{2}$ to the atmosphere.

Currently, the project has other on-going tasks aiming a deeper knowledge of the current state of the electric distribution grid to identify the improvements required to support this intervention, as well as the environmental, social and economic implications of the plan. First results seem to recommend a smooth implantation of the facilities along a decade and should end with a first proposal of optimal energy mix.

\section{References}

[1] International Energy Agency, World Energy Outlook 2006

[2] Ministerio de Industria, Comercio y Turismo, Plan de Energías Renovables de España 2005-2010, Instituto para la Diversificación y el Ahorro de la Energía

[3] Junta de Andalucía, Anuario Estadístico de Andalucía 2010. Instituto de Estadística de Andalucía. Consejería de Economía, Innovación y Ciencia

[4] Terrados, J., Metodología para la planificación y el desarrollo de las energías renovables en el ámbito regional. Caso de aplicación: la provincia de Jaén, 2005. Tesis Doctoral dirigida por el Dr. Gabino Almonacid Puche.

[5] Sánchez, S., Moya, A.J., Moya, M., Romero, I., Torrero, R., Bravo, V., San Miguel, M.P., Aprovechamiento del residuo de poda del olivar, Ing. Quim., 34(391), 2002, pp. 194-202

[6] Junta de Andalucía, Potencial energético de la biomasa residual agrícola y ganadera en Andalucía, 2008, Consejería de Agricultura y Pesca

[7] Junta de Andalucía, Potencial y Aprovechamiento energético de la biomasa del olivar en Andalucía, 2007, Agencia Andaluza de la Energía

[8] Šúri, M., and Hofierka, J., A new GIS-based solar radiation model and its application to photovoltaic assessments, Transactions in GIS, 2, 2004, pp. 175-190

[9] Rigollier, C., Bauer, O., Wald, L., On the clear sky model of the ESRA-European Solar Radiation Atlas-with respect to the Heliosat method, Solar Energy, 68(1), 2000, pp. 3348

[10] Skamarock, W., et al., A description of the Advanced Research WRF Version 3, 2008, Technical Report, National Center for Atmospheric Research, Boulder, CO, USA

[11]Diputación Provincial de Jaén, Proyecto de Promoción de Parques Eólicos Singulares en la Provincia de Jaén, 2007, Agencia de Gestión Energética de Jaén 